\title{
Acetone as biomarker for ketosis buildup capability - a study in healthy individuals under combined high fat and starvation diets
}

\author{
Amlendu Prabhakar ${ }^{1 \dagger}$, Ashley Quach ${ }^{1 \dagger}$, Haojiong Zhang ${ }^{1}$, Mirna Terrera', David Jackemeyer ${ }^{1}$, Xiaojun Xian ${ }^{1}$,
} Francis Tsow ${ }^{1}$, Nongjian Tao ${ }^{1,3}$ and Erica S Forzani ${ }^{1,2^{*}}$

\begin{abstract}
Background: Ketogenic diets are high fat and low carbohydrate or very low carbohydrate diets, which render high production of ketones upon consumption known as nutritional ketosis (NK). Ketosis is also produced during fasting periods, which is known as fasting ketosis (FK). Recently, the combinations of NK and FK, as well as NK alone, have been used as resources for weight loss management and treatment of epilepsy.
\end{abstract}

Methods: A crossover study design was applied to 11 healthy individuals, who maintained moderately sedentary lifestyle, and consumed three types of diet randomly assigned over a three-week period. All participants completed the diets in a randomized and counterbalanced fashion. Each weekly diet protocol included three phases: Phase 1 A mixed diet with ratio of fat: (carbohydrate + protein) by mass of 0.18 or the equivalence of $29 \%$ energy from fat from Day 1 to Day 5. Phase 2- A mixed or a high-fat diet with ratio of fat: (carbohydrate + protein) by mass of approximately $0.18,1.63$, or 3.80 on Day 6 or the equivalence of $29 \%, 79 \%$, or $90 \%$ energy from fat, respectively. Phase 3 - A fasting diet with no calorie intake on Day 7. Caloric intake from diets on Day 1 to Day 6 was equal to each individual's energy expenditure. On Day 7, ketone buildup from FK was measured.

Results: A statistically significant effect of Phase 2 (Day 6) diet was found on FK of Day 7, as indicated by repeated analysis of variance (ANOVA), $F(2,20)=6.73, p<0.0058$. Using a Fisher LDS pair-wise comparison, higher significant levels of acetone buildup were found for diets with 79\% fat content and 90\% fat content vs. 29\% fat content (with $p=0.00159^{* *}$, and $0.04435^{* *}$, respectively), with no significant difference between diets with $79 \%$ fat content and 90\% fat content. In addition, independent of the diet, a significantly higher ketone buildup capability of subjects with higher resting energy expenditure $\left(R^{2}=0.92\right)$, and lower body mass index $\left(R^{2}=0.71\right)$ was observed during FK.

Keywords: Ketogenic diet, Breath ketone, Acetone, Fasting ketosis, Nutritional ketosis, Starvation

\section{Background}

Ketosis or ketoacidosis is a physiological state sharing an outcome of increased ketone levels in the blood due to relatively high lipid oxidation rates. Monitoring rapid and dramatic changes in ketones offers us valuable diagnoses for lipid oxidation and metabolism [1]. Several studies have clearly demonstrated that metabolic

\footnotetext{
* Correspondence: eforzani@asu.edu

${ }^{\dagger}$ Equal contributors

${ }^{1}$ Current address: Center for Bioelectronics and Biosensors, the Biodesign Institute, Arizona State University, 1001 S McAllister Ave., Tempe, AZ 85287, USA ${ }^{2}$ School for Engineering of Matter, Transport, and Energy, Arizona State University, 501 E. Tyler Mall, Tempe, AZ 85287, USA

Full list of author information is available at the end of the article
}

imbalance in type I diabetes has led to ketoacidosis $(K A D)$ of blood, leading to elevated ketone levels with arterial $\mathrm{pH}<7.3$ and bicarbonate $<15 \mathrm{mEq} / \mathrm{L}$, and causing arresting of major organ functions [2]. In addition to acidosis, studies have also shown that elevated ketone levels are a natural metabolic response to negative energy balance, wherein caloric intake is smaller than total energy expenditure, and the body burns stored fat to produce the needed energy [3], leading to a state of ketosis known as fasting ketosis (FK). FK has been used as an indicator of the effectiveness of weight loss [4-6]. Furthermore, ketosis also occurs in situations where caloric

Ciomed Central

or the article

(c) 2015 Prabhakar et al. This is an Open Access article distributed under the terms of the Creative Commons Attribution License (http://creativecommons.org/licenses/by/4.0), which permits unrestricted use, distribution, and reproduction in any medium, provided the original work is properly credited. The Creative Commons Public Domain Dedication waiver (http:// creativecommons.org/publicdomain/zero/1.0/) applies to the data made available in this article, unless otherwise stated. 
intake equals total energy expenditure, specifically in a diet that contains high percentage of fat $(>60 \%)$ and/or low carbohydrate. This state of ketosis has been referred to as nutritional ketosis (NK) $[7,8]$. NK has been investigated as a treatment for epilepsy because ketones are thought to provide energy to the brain, which reduces epileptic seizures $[9,10]$. In addition, ketosis buildup capability resulting from a combination of NK and FK has been associated with weight loss efficiency and positive health outcomes [11-13].

While KAD, FK, and NK are well-defined clinical and physiological states that can produce high levels of ketones, there are other conditions, such as exercise that can actually decrease ketone levels in the blood by using ketone as an energy source in the muscles $[14,15]$. For the reasons described above, ketone levels are affected by several factors, such as energy balance, diet composition, and physical activities, all of which underscore the importance of determining the accuracy of ketone levels. Previous studies, including KAD, FK, NK, and exerciserelated ketosis have significantly advanced the field of ketosis. However, analyses including characterization of analytical, physiological, and behavioral conditions are needed in the literature to improve the understanding of ketone level profiles in connection with monitoring of lipid oxidation, generation, utilization, and clearance of ketones under free-living conditions.

Under ketosis or ketoacidosis, the liver metabolizes fatty acids to produce two water-soluble types of ketones: acetoacetic acid and beta-hydroxybutyric acid. A third type of ketone, i.e., acetone, is also produced by the enzymatic decarboxylation of acetoacetic acid. Due to its high vapor pressure, acetone crosses the membrane barrier into the alveoli of the lung and the airway. As a result, acetone is normally present in breath. Breath acetone has been considered a reliable indicator of ketosis in adults consuming ketogenic meals [16] and can be used to predict plasma ketone bodies in children with epilepsy who are on a ketogenic diet [17]. Most recently, breath acetone has been used as a new ketone biomarker because it is non-invasive, convenient, and an accurate reflection of the body's ketone level [18].

In the present work, our focus is on both intermittent high-fat diets (NK) and fasting diets (FK) with an aim to: 1) evaluate the effectiveness of combined NK and FK in ketone buildup capability; and 2) study how ketone buildup capability is associated with intrinsic characteristics of individuals. First, we systematically studied the effect of fat-rich diets on fasting ketone levels to determine if lipid metabolism can respond to the fat content in different diets. Diets with different fat content were provided to 11 healthy individuals in order to maintain their energy balance (i.e., calorie intake equals to energy expenditure). Breath acetone detection was then used to analyze the lipid metabolism response of these individuals during a fasting day after the high-fat diet day.

Second, we analyzed how the acetone buildup capability of the healthy individual depended on resting energy expenditure and physical characteristics, such as body mass index and body fat percentage.

In this diet study, we used Selected Ion Flow TubeMass Spectrometry (SIFT-MS) as a primary method for monitoring trace acetone gas in exhaled breath [19-21]. A high level of ketosis shown by elevated acetone in exhaled breath as measured by SIFT-MS was verified against measurements obtained with the commonly used blood and urine ketone detection method. Mass spectrometerbased methods, especially SIFT-MS, are currently the proven technology for most accurate detection of ketone levels in breath $[16,18,22]$. Blood ketone was measured using ketone strips with Precision Xtra meter, which have proven to be highly precise $[23,24]$. Urinary ketone was determined using Ketostix strips, as recommended by the American Diabetes Association for monitoring ketones in urine [25].

\section{Methods}

\section{Subjects}

Eleven (11) healthy volunteers (7 male and 4 female) with an average age of $27 \pm 7$ years and average BMI of $23.1 \pm 5$ participated in the study. Physical activity levels (PAL) of the subjects were classified based on reported frequency, duration, and type of physical activities from the Compendium of Physical Activities [26]. Additionally, all subjects completed the International Physical Activity Questionnaire (IPAQ - 7 day, self-administered format), which is widely used to classify a population's PAL as "Low", "Moderate", or "High" [27]. Based on the responses, the PAL for all subjects in this study was classified as "Low" or sedentary lifestyle. The characteristics of each subject are summarized in Table 1 . None of the subjects was on regular medication, nor had any history of respiratory diseases or diabetes, which enabled the comparison of ketone buildup capabilities under conditions of healthy acid-base balance and alveolar gas exchange [28]. All the subjects were educated about the study design and purpose. An informed consent form approved by the Institutional Review Board at Arizona State University (IRB protocol number: 1012005855) was obtained from each subject prior to the study.

\section{Physiological and metabolic parameters}

Total energy expenditure (TEE) for each subject of the study was estimated according to TEE $=$ PAL * REE, where REE was the Resting Energy Expenditure assessed by indirect calorimetry method, using a mobile metabolism tracker named "Breezing" from Breezing Co., AZ (www.breezing.com); and PAL was the Physical Activity 
Table 1 Physiological and metabolic parameters of 11 subjects enrolled in the study

\begin{tabular}{|c|c|c|c|c|c|c|c|}
\hline Subject & Age & Gender & $\begin{array}{l}\text { Weight } \\
\text { (kg) }\end{array}$ & $\begin{array}{l}\text { Height } \\
(\mathrm{m})\end{array}$ & BMI & $\begin{array}{l}\text { Body } \\
\text { fat } \%\end{array}$ & TEE (kcal/day) \\
\hline 1 & 28 & M & 79.1 & 1.68 & 28.0 & 24.2 & 1899 \\
\hline 2 & 41 & $\mathrm{~F}$ & 49.4 & 1.69 & 17.3 & 13.1 & 1398 \\
\hline 3 & 35 & M & 77.1 & 1.88 & 21.8 & 10.8 & 1800 \\
\hline 4 & 21 & M & 65.6 & 1.82 & 19.8 & 8.6 & 3030 \\
\hline 5 & 24 & M & 90.5 & 1.68 & 32.1 & 29.0 & 2283 \\
\hline 6 & 23 & M & 70.0 & 1.80 & 21.6 & 12.4 & 2592 \\
\hline 7 & 37 & $\mathrm{~F}$ & 63.3 & 1.61 & 24.4 & 33.3 & 2112 \\
\hline 8 & 23 & M & 85.5 & 1.78 & 27.0 & 21.4 & 1969 \\
\hline 9 & 23 & M & 94.3 & 1.93 & 25.3 & 20.0 & 3398 \\
\hline 10 & 25 & $\mathrm{~F}$ & 52.8 & 1.70 & 18.3 & 10.8 & 2232 \\
\hline 11 & 20 & $\mathrm{~F}$ & 52.5 & 1.69 & 18.4 & 12.4 & 2238 \\
\hline
\end{tabular}

M: Male, F: Female, BMI: Body Mass Index, Body Fat \%: represents values assessed by bio-impedance method (see text for details), and TEE: Total Energy Expenditure.

Level defined by IPAQ, and quantified as follows: PAL $($ female $)=1.179$, PAL (male): 1.274 [29]. The sensing principle of the indirect calorimeter used for REE [30] was validated against the Douglas bag method [31]. Resting condition of the subjects for assessment of REE included overnight fasting, 12-hour period of no strenuous exercise, no-caffeine ingestion prior to the measurement, and a resting position for assessment that required the subject to hold his/her head on a comfortable surface. The subjects rested for 10 minutes before the measurement, and were instructed to relax and breathe normally during the measurement.

A bioelectrical impedance analysis using body composition analyzer SC-240 from Tanita Co. (http://www.tanita.com) was conducted to measure the percentage of body fat. In addition, weight, height, and BMI (ratio of weightto-height squared $\left(\mathrm{Kg} /(\text { meters })^{2}\right)$ ) were assessed for each subject.

\section{Diet study design}

Three different diets (Diets A, B, and C) with varying ratios of fat to total carbohydrate and protein by mass of approximately $0.18,1.63$, and 3.80 (Table 2 ) were applied to the study (Figure 1). In other words, it was the equivalence of $29 \%, 79 \%$, and $90 \%$ of daily dietary caloric intake coming from fat for Diets $\mathrm{A}, \mathrm{B}$, and $\mathrm{C}$, respectively. Diet $\mathrm{A}$ was high in carbohydrate and low in fat; while Diet $\mathrm{C}$ was the opposite. In Diet B, even though \% energy from fat was lower, it was still a dominant energy source with equal contributions from carbohydrates and protein. Detailed diet composition for each subject for all three diets can be reviewed in the Additional file 1 .

Each subject's physical and metabolic parameters, including height, weight, percentage of body fat, resting energy expenditure (REE), and physical activity level (PAL), were measured before the start of the study. TEE was calculated from each individual's REE and PAL.

The study was carried out over a three-week period on each subject. Table 2 describes in detail the fat:(carbohydrate + protein) ratio by mass, as well as an example of the nutritional information of each diet. Foods with similar nutrition facts could be exchanged to satisfy personal taste as long as fat:(carbohydrate + protein) ratio by mass and TEE remained the same. The subjects followed 3 diet protocols. Each diet protocol included 3 phases with identical phases 1 and 3 , and a variable phase 2 (Figure 1), as follows:

- Phase 1: The subjects followed Diet A on the first five days (Day 1-5) of the week. Diet A included a fat:(carbohydrate + protein) ratio by mass of approximately 0.18 or $29 \%$ of energy from fat.

- Phase 2: The subjects followed a randomized diet of Diet A, B, or C, with ratio of fat:(carbohydrate + protein) by mass of approximately $0.18,1.63$, or 3.80 (29\%, $79 \%$, or $90 \%$ of energy from fat), respectively on the sixth day (Day 6) of the week.

- Phase 3: The subjects followed a fasting protocol where only non-caloric drinks were allowed on the $7^{\text {th }}$ day (Day 7) of the week.

Each of the 11 subjects was randomly assigned among the three diet protocol over three weeks of the study, which took place from May 2013 through August 2013. Each of the 11 subjects completed all 3 diet interventions in a randomized and counterbalanced fashion. The subjects were provided with the food during Day 1-6 and ate the food under free-living conditions. On the morning of Day 7 (fasting day), the subjects were questioned to ensure diet compliance. The subjects remained at the research facility performing desk work (mostly computer work), and the research personnel who interacted with the subjects throughout the day, assessed compliance to fasting.

\section{Measurement protocol}

The measurement protocol consisted of breath ketone (acetone) measurements performed at baseline, and during acetone buildup.

\section{Baseline acetone levels}

The measurements were taken after phase 1 , and right before starting phase 2, in the morning of Day 6 at 10:00 am. The baseline levels reflected the acetone level after intake of Diet A on the previous days. 
Table 2 Example of diet compositions used in the study for subject \#1 with total energy expenditure of 1899 kcals/day

\begin{tabular}{|c|c|c|c|c|c|c|c|c|c|c|}
\hline & \multirow[t]{2}{*}{ Food } & \multirow[t]{2}{*}{ Amount } & \multicolumn{2}{|l|}{ Total F (g) } & \multirow[t]{2}{*}{ Total C (g) } & \multirow[t]{2}{*}{ Total P (g) } & \multirow[t]{2}{*}{ Fiber (g) } & \multirow{2}{*}{$\begin{array}{l}\text { Cholesterol } \\
\text { (mg) }\end{array}$} & \multirow{2}{*}{$\begin{array}{l}\text { Total } \\
\text { calories } \\
\text { (kcal) }\end{array}$} & \multirow{2}{*}{$\begin{array}{l}\text { Ratio of fat: } \\
\text { (carb + protein) } \\
\text { by mass }\end{array}$} \\
\hline & & & Sat. F (g) & Unsat. $F(g)$ & & & & & & \\
\hline \multirow[t]{11}{*}{ Diet A } & Black Coffee (no cream, no sugar) & 2 cup & 0.0 & 0.0 & 0.0 & 0.6 & 0.0 & 0.0 & 2 & 0.18 \\
\hline & Classic pork breakfast sausage & 1 patty & 2.0 & 3.5 & 0.0 & 4.0 & 0.0 & 40.0 & 66 & \\
\hline & Yoplait Yogurt & 1 serving & 1.0 & 0.5 & 33.0 & 5.0 & 0.0 & 10.0 & 165 & \\
\hline & Chicken Alfredo with Fettuccine and Broccoli & 1 serving & 9.3 & 8.0 & 50.0 & 26.0 & 5.0 & 100.0 & 470 & \\
\hline & Sesame Noodle with Vegetables & 1 serving & 0.5 & 2.0 & 55.0 & 10.0 & 7.0 & 0.0 & 280 & \\
\hline & Gala Apple (small, raw, with skin) & 2 & 0.0 & 0.0 & 32.0 & 0.0 & 5.0 & 0.0 & 132 & \\
\hline & Sweet and Sour Chicken with White Rice & 0.5 serving & 1.5 & 5.5 & 28.0 & 5.0 & 1.5 & 10.0 & 195 & \\
\hline & Chopped pecans & $17 \mathrm{~g}$ & 1.1 & 11.0 & 2.4 & 1.8 & 1.8 & 0.0 & 125 & \\
\hline & Beef Steak and Noodles & 1 serving & 6.0 & 8.0 & 51.0 & 33.0 & 4.0 & 105.00 & 462 & \\
\hline & Total & & 60.4 & & 251.4 & 85.4 & 24.3 & 265 & 1897 & \\
\hline & $\%$ Energy from food & & $29 \%$ & & $53 \%$ & $18 \%$ & & & & \\
\hline \multirow[t]{8}{*}{ Diet B } & Classic pork breakfast sausage & 4 patty & 8.0 & 14.0 & 0.0 & 16.0 & 0.0 & 160.0 & 262 & 1.63 \\
\hline & Pine nuts & $57 \mathrm{~g}$ & 5.2 & 63.2 & 22.8 & 11.4 & 3.1 & 0.0 & 752 & \\
\hline & Deli Delux American Cheese & 2 slice & 8.0 & 6.0 & 0.0 & 8.0 & 0.0 & 40.0 & 158 & \\
\hline & Avocado & $95 \mathrm{~g}$ & 2.0 & 11.3 & 7.6 & 1.9 & 6.5 & 0.0 & 158 & \\
\hline & Philadelphia Cream cheese & $10 \mathrm{~g}$ & 1.9 & 1.3 & 0.4 & 0.7 & 0.0 & 11.0 & 33 & \\
\hline & Roasted Almonds & $84 \mathrm{~g}$ & 3.0 & 42.0 & 15.0 & 18.0 & 9.0 & 0.0 & 537 & \\
\hline & Total & & 165.9 & & 45.8 & 56 & 46.9 & 211 & 1,900 & \\
\hline & $\%$ Energy from food & & $79 \%$ & & $9 \%$ & $12 \%$ & & & & \\
\hline \multirow[t]{8}{*}{ Diet C } & Mild sausage patties & 6 patty & 27.5 & 44.5 & 0.0 & 24.0 & 0.0 & 1500.0 & 744 & 3.80 \\
\hline & Avocado & $64 \mathrm{~g}$ & 1.3 & 7.7 & 5.1 & 1.3 & 4.4 & 0.0 & 106 & \\
\hline & Heavy whipping cream & $85 \mathrm{~mL}$ & 21.6 & 12.4 & 0.0 & 0.0 & 0.0 & 117.0 & 306 & \\
\hline & Chopped pecans & $41 \mathrm{~g}$ & 2.7 & 26.6 & 5.9 & 4.4 & 4.3 & 0.0 & 305 & \\
\hline & Smart balance buttery spread & $43 \mathrm{~g}$ & 8.3 & 18.2 & 0.0 & 0.0 & 0.0 & 0.0 & 238 & \\
\hline & Pine nuts & $15 \mathrm{~g}$ & 1.4 & 16.6 & 6.0 & 3.0 & 1.0 & 0.0 & 198 & \\
\hline & Total & & 188.8 & & 17 & 32.7 & 9.7 & 1617 & 1,897 & \\
\hline & $\%$ Energy from food & & $90 \%$ & & $3 \%$ & $7 \%$ & & & & \\
\hline
\end{tabular}




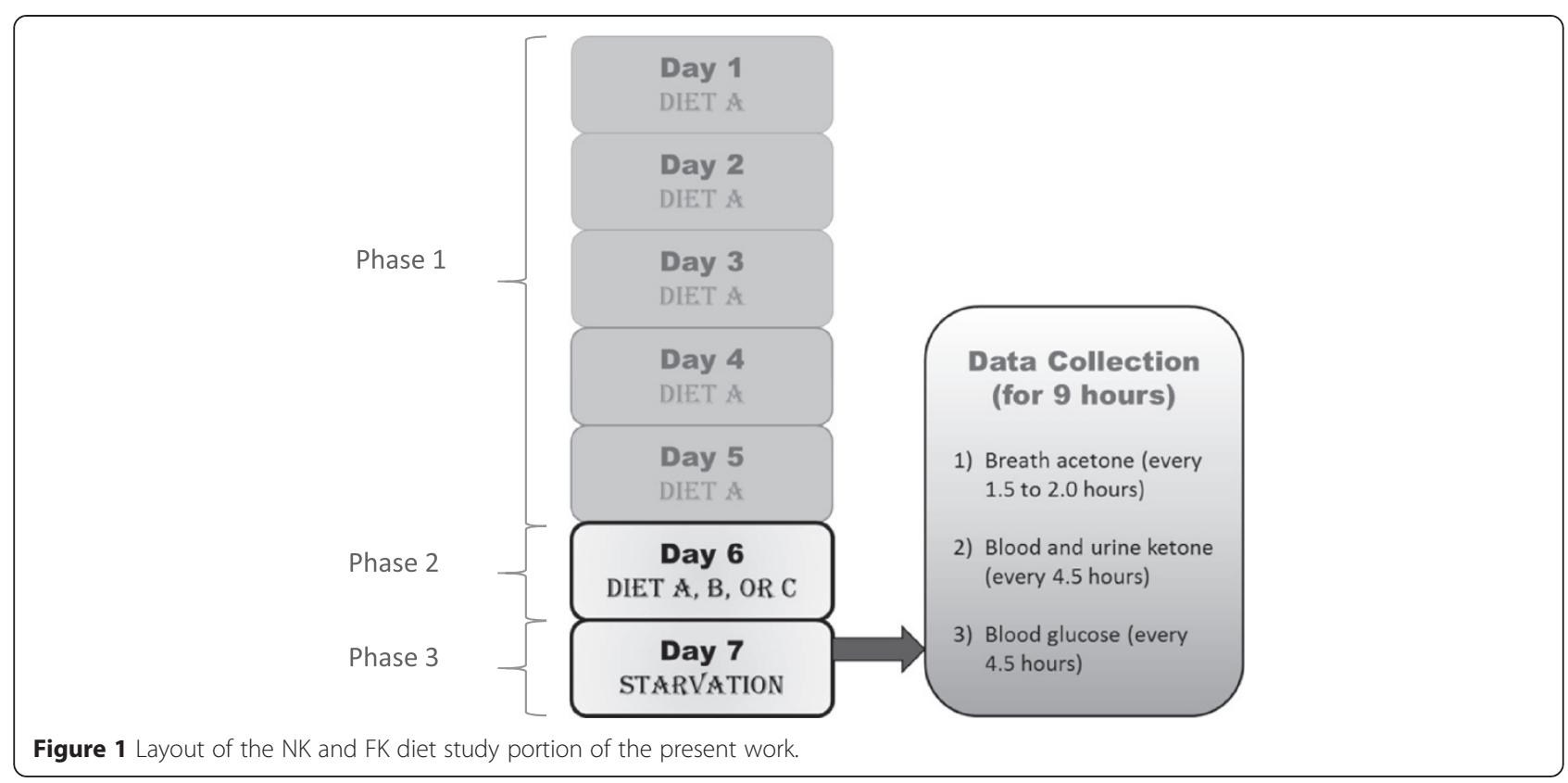

\section{Acetone buildup levels}

These measurements were taken after phase 2 at 12 hours from the last meal on Day 6 (which was consumed at 10:00 pm), and at the beginning of Phase 3 starting at 10:00 am in the morning of Day 7 (fasting day) for a period of 9 hours every 1.5 to 2 hours.

The measurement procedure was repeated during each weekly diet protocol. The acetone buildup was calculated as the difference between the acetone levels measured after 21 hours of fasting (Day 7) and the baseline level determined in the morning (before breakfast) of phase 2 (Day 6, after consumption of diet A, which was a carbohydrate-rich diet and low-fat diet on Day 5). The method of determining the baseline was chosen over a random measurement of acetone during a regular or uncontrolled day of the subject since breath acetone is known to be affected by diet and physical activity during the day [32].

\section{Breath ketone measurements}

Concentration of acetone was assessed from exhaled breath using Selected Ion Flow Tube - Mass Spectrometer (SIFT-MS) (Instrument Science, Profile Series, Crewe, UK) in multiple ion monitoring (MIM) modes. $\mathrm{H}_{3} \mathrm{O}^{+}(\mathrm{m} / \mathrm{z}=19)$ was chosen as the precursor ion for reaction with breath samples with ultra-high purity (99.999\%) helium as the carrier gas. Precursor ion peaks at $\mathrm{m} / \mathrm{z}$ of $19,37,55$, and 73 corresponding to hydrated $\mathrm{H}_{3} \mathrm{O}^{+} \cdot \mathrm{nH}_{2} \mathrm{O}(\mathrm{n}=0,1,2,3)$ and product ion peaks after reaction with acetone at $\mathrm{m} / \mathrm{z}$ of 59 and 77 corresponding to $\mathrm{C}_{3} \mathrm{H}_{7} \mathrm{O}^{+}$and its hydrate $\mathrm{C}_{3} \mathrm{H}_{7} \mathrm{O}^{+} \cdot \mathrm{H}_{2} \mathrm{O}$, which were monitored. Quantification of the concentration was performed in the MIM mode by taking into account the known reaction rate coefficients for $\mathrm{H}_{3} \mathrm{O}^{+}$and acetone reaction, and the measured ion flow velocity [22]. It should be noted that this method does not measure the dihydrate of protonated acetone at $\mathrm{m} / \mathrm{z}$ of 95 , which represents about $10-15 \%$ of total signal combining $\mathrm{m} / \mathrm{z}$ of 59,77 , and 95. Individual subject breath was collected in a 6 L clean bag before immediately being measured with SIFT-MS using a pump at a constant flow rate. The flow rate was monitored and adjusted in the analysis by monitoring the water vapor level in the samples.

\section{Other measurements}

Blood and urine ketone as well as blood glucose levels were measured every 4.5 hours for correlations with breath ketone levels. Blood ketones were measured using Precision Xtra, an electrochemical capillary blood monitor from Abbott. This monitor determined the blood ketone: beta-hydroxybutyrate $(\beta-\mathrm{OHB})$. Standard operation procedures as prescribed by the monitor were used for the analysis. The test meter was turned on while a ketone strip was inserted to prepare for the test. The subjects' fingertips were cleaned with an alcohol swab and dried before being pricked with the provided lancing device. A drop of blood was applied to the assigned spot of the ketone strip. Ketone levels were read from the display 10 seconds after blood was delivered to the meter.

Meanwhile, urinary ketone measurements were performed using over-the-counter reagent strips for urinalysis (Ketostix from Bayer). The strip monitored acetoacetic acid (AcAcA), upon reaction with nitroprusside salt. The reagent end of the strip was passed through the urine stream, changing the color on the strip. The color was then compared to the color chart provided with the product 15-30 seconds after the reaction. 
In addition to ketone analysis, blood glucose was measured for comparison using Precision Xtra, an electrochemical capillary blood monitor from Abbott, and glucose strips, according to the standard procedure as prescribed by the vendors. All ketones and blood glucose measurements were carried out simultaneously for direct comparison.

\section{Statistical analysis}

OriginPro software was used for all statistical analysis. The effect of a high-fat diet on the level of ketosis was analyzed for statistical significance by performing a twoway repeat measurement analysis of variance (ANOVA). Pair-wise comparisons of three data sets obtained from 11 subjects were performed using Fisher LSD tests. The data sets were related to the acetone buildup concentration due to the three different diets consumed on separate study weeks. In addition, relationships between ketosis and physiological parameters of the subjects were analyzed using nonlinear regression models keeping the physiological parameter as the independent variable.

\section{Results and discussions}

\section{Effect of diet on ketosis}

As mentioned earlier, each week included a different diet taken during phase 2 (Day 6) (Figure 1). The diets (Diets $\mathrm{A}, \mathrm{B}$, and C) differed in the ratios of fat vs. carbohydrate and protein as shown in Table 2. Figure 2 shows the acetone buildup levels as a function of the ratios of fat to total carbohydrate and protein by mass of the three diets. Table 3 summarizes the results from Figure 2, and related statistical tests, and analysis of differential increase percentage of acetone buildup concentration of one diet with respect to another (see below for more details). Figure 2 clearly shows that fasting induced significant increases in breath acetone levels after each weekly diet (Diet A, B, or C). To evaluate statistical differences between the 3 groups, analysis of variance (ANOVA) was performed, and showed $\mathrm{F}(2,20)=6.73, \mathrm{p}<0.0058$, which indicated the groups are statistically different in significant ways, for a $\mathrm{p}$ value of 0.05 .

In order to further compare the effect of the different diets on the acetone buildup concentration, a Fisher LDS pair-wise comparison was performed (Table 3). For $\mathrm{p}$ value of 0.05 , the results indicated significant difference between Diet B with respect to Diet A $\left(p=0.00156^{* * * *}\right)$, and Diet $\mathrm{C}$ with respect to Diet $\mathrm{A}\left(\mathrm{p}=0.04435^{* * * *}\right)$, but no significant difference between Diet $B$ with respect to Diet C $\left(\mathrm{p}=0.14797^{*}\right)$. It is noteworthy that 1$)$ higher fat ratio diets (Diet B, and Diet C) produced statistically significant acetone buildup concentrations than the lower fat ratio diet (Diet A), 2) higher fat ratio diets (Diet B and Diet C) did not show statistically significant differences in the acetone buildup concentrations, meaning that levels of
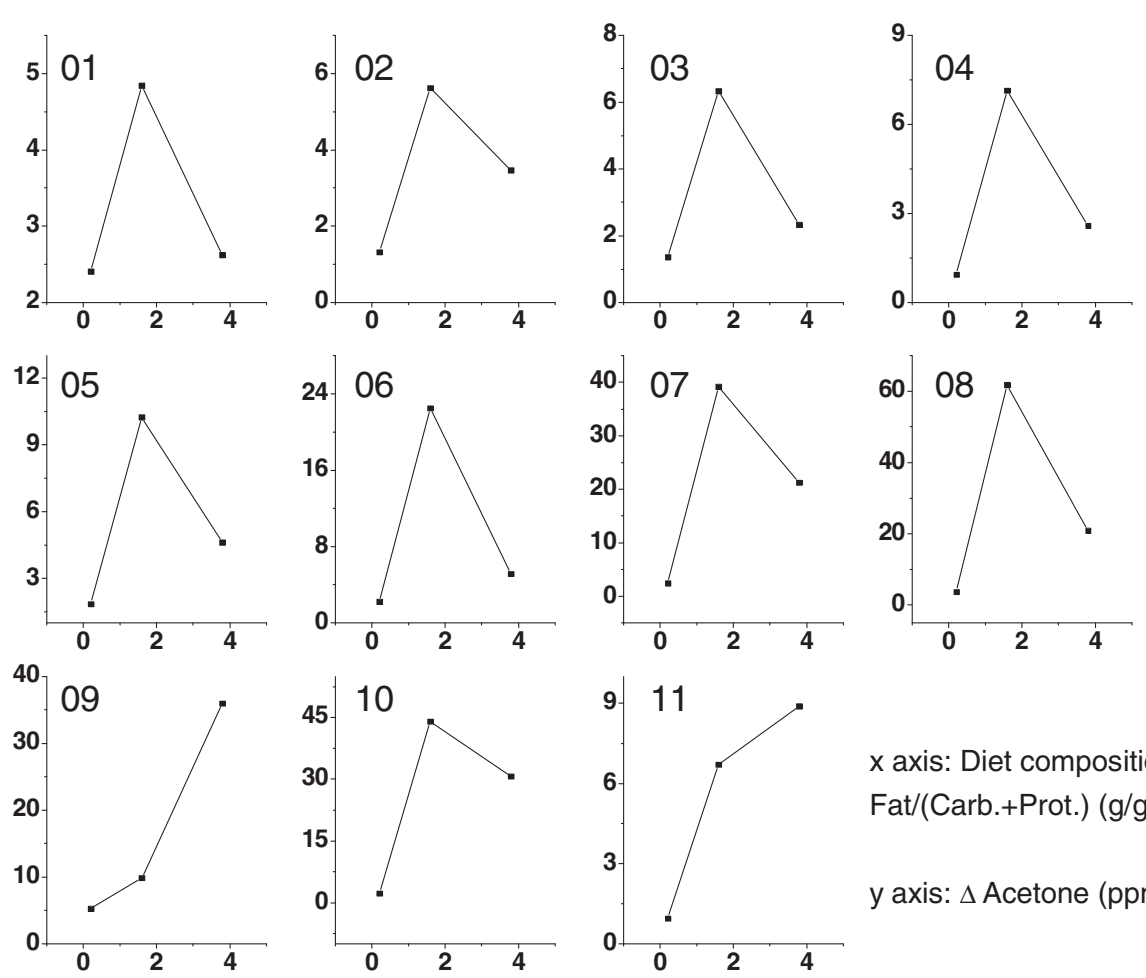

$x$ axis: Diet composition

Fat/(Carb.+Prot.) (g/g)

y axis: $\Delta$ Acetone (ppmV)

Figure $\mathbf{2}$ Changes in acetone during phase 3, starvation, after different diet compositions for 11 subjects. The diets are defined by the ratio of fat to total carbohydrate and protein by mass, which are plotted on the $x$-axis. The change in acetone in ppmV is plotted on the $y$-axis. 
Table 3 Comparative table of the effect of Diet A, Diet B, and Diet $C$ on acetone buildup concentration under fasting conditions

\begin{tabular}{|c|c|c|c|c|c|c|}
\hline \multirow[t]{2}{*}{ Index } & \multicolumn{3}{|c|}{ Final Acetone Buildup Concentration (ppmV) } & \multicolumn{3}{|c|}{ Difference of Acetone Buildup Concentration (ppmV) } \\
\hline & Diet A & Diet B & Diet C & $\Delta_{\text {Diet B-Diet A }}$ & $\Delta_{\text {Diet C-Diet A }}$ & $\Delta_{\text {Diet B-Diet C }}(\%)$ \\
\hline Subject 1 & 2.40 & 4.84 & 2.62 & $2.44(102 \%)$ & $0.22(9 \%)$ & $2.22(+85 \%)$ \\
\hline Subject 2 & 1.32 & 5.63 & 3.46 & $4.30(327 \%)$ & $2.14(162 \%)$ & $2.17(+62 \%)$ \\
\hline Subject 3 & 1.37 & 6.33 & 2.33 & $4.97(362 \%)$ & $0.97(70 \%)$ & $4.00(172 \%)$ \\
\hline Subject 4 & 0.94 & 7.13 & 2.60 & $6.19(659 \%)$ & $1.66(177 \%)$ & $4.53(174 \%)$ \\
\hline Subject 5 & 1.85 & 10.24 & 4.63 & $8.39(454 \%)$ & $2.78(150 \%)$ & $5.61(121 \%)$ \\
\hline Subject 6 & 2.22 & 22.49 & 5.15 & 20.27 (913\%) & $2.93(132 \%)$ & 17.35 (337\%) \\
\hline Subject 7 & 2.43 & 39.18 & 21.24 & $36.75(1512 \%)$ & $18.81(774 \%)$ & 17.94 (84\%) \\
\hline Subject 8 & 3.73 & 61.76 & 20.83 & $58.03(1556 \%)$ & $17.10(458 \%)$ & $40.93(196 \%)$ \\
\hline Subject 9 & 5.27 & 9.81 & 35.93 & $4.54(86 \%)$ & $30.66(582 \%)$ & $-26.12(-72 \%)$ \\
\hline Subject 10 & 2.28 & 44.04 & 30.75 & $41.76(1832 \%)$ & 28.47 (1249\%) & $13.29(43 \%)$ \\
\hline Subject 11 & 0.94 & 6.71 & 8.89 & $5.77(614 \%)$ & 7.95 (846\%) & $-2.18(-24 \%)$ \\
\hline Mean & 2.25 & 19.83 & 12.58 & \multirow{3}{*}{$\begin{array}{l}100 \% \text { data show final acetone buildup } \\
\text { concentration from Diet } \mathrm{B}>\text { acetone } \\
\text { buildup concentration from Diet } \mathrm{A}\end{array}$} & \multirow{3}{*}{$\begin{array}{l}100 \% \text { data show final acetone buildup } \\
\text { concentration from Diet } \mathrm{C}>\text { acetone } \\
\text { buildup concentration from Diet A }\end{array}$} & \multirow{3}{*}{$\begin{array}{l}82 \% \text { data show final acetone } \\
\text { buildup concentration from } \\
\text { Diet } B>\text { acetone buildup } \\
\text { concentration from Diet } C\end{array}$} \\
\hline Standard Deviation & 1.29 & 19.65 & 12.40 & & & \\
\hline ANOVA $p$ value & $<0.0058$ & & & & & \\
\hline
\end{tabular}

Fisher Test $p$ value of Diet A and Diet B $0.00159^{* *}$

Fisher Test $p$ value of Diet A and Diet C $0.04435^{* *}$

Fisher Test $p$ value of Diet $B$ and Diet C $0.14797^{*}$

$\Delta_{\text {Diet B-Diet A: }}$ Difference of Acetone Buildup Concentration between Diet B and Diet A.

$\Delta_{\text {Diet C-Diet A }}$ Difference of Acetone Buildup Concentration between Diet C and Diet A.

$\Delta_{\text {Diet B-Diet }}$ : Difference of Acetone Buildup Concentration between Diet B and Diet C.

"\%" indicates the percentage difference between acetone buildup concentration of:

1) Diet $B$ with respect to Diet $A$, taking Diet $A$ as reference: $[($ Diet $B$ - Diet A) / Diet A] x 100;

2) Diet $C$ with respect to Diet $A$, taking Diet $A$ as reference: [(Diet $C$ - Diet $A) /$ Diet $A] \times 100$;

to Diet $C$, taking Diet $C$ as reference: 
acetone buildup produced from a $79 \%$ fat content diet (Diet $\mathrm{B}=1.63: 1$ fat:(carbohydrates + protein)) were statistically similar to those levels produced from a $90 \%$ fat content $\operatorname{diet}$ (Diet $\mathrm{C}=3.80: 1$ fat:(carbohydrates + protein)).

Furthermore, analysis of differential increase percentage of acetone buildup concentration at individual levels (Table 3) indicated the following:

Diet B vs. Diet A: $100 \%$ of individuals showed increase in acetone buildup concentration above $86 \%$ and up to 1800\% when comparing Diet B with Diet A, using Diet A as reference (This is in line with Fisher LDS test). Diet $C$ vs. Diet A: $100 \%$ of the individuals showed increase in acetone buildup concentration above $9 \%$ and up to $1248 \%$ when comparing Diet C with Diet A, using Diet $\mathrm{A}$ as reference (This is in line with Fisher LDS test).

Diet $B$ vs. Diet C: $82 \%$ of the individuals showed increase in acetone buildup concentration above 43\% and up to $337 \%$ when comparing Diet B with Diet C, using Diet $\mathrm{C}$ as reference.

With regard to the last comparison (Diet $B$ vs. Diet C), it is noteworthy that Diet B and Diet $C$ did not show statistically significant differences in acetone buildup concentrations at population levels due to intrinsically high dispersion of the values across the population (mean \pm SD of Diet $B=(19.83 \pm 19.64)$, mean \pm SD of Diet $C=(12.58 \pm 12.40) \mathrm{ppmV})$. However, an analysis of the differences between acetone buildup concentrations at individual levels indicates 9 of 11 individuals had higher acetone buildup with the relatively lower fat ratio diet (Diet $\mathrm{B}=79 \%$ fat content, 1.63:1 fat:(carbohydrates + protein)) compared to the higher fat diet $(90 \%$, 3.80:1 fat:(carbohydrates + protein)). Therefore, the higher fat diet level did not show higher buildup to higher levels of ketosis, and some individuals may have a better development of ketosis with lower $79 \%$ vs $90 \%$ fat content diet.

The plateau in ketosis at higher fat content $\operatorname{diet}($ Diet C) suggest two potential implications: 1) Excessive ketone production may induce more ketone utilization as a fuel for the heart, muscle and/or brain [3]; 2) Ketone production may shut down when excessive ketone levels are produced. Since, the ketone level in breath is reflective of ketone level in blood, and these levels are a consequence of production vs. utilization, the cause of the most dominant factor responsible for Diet C's outcome remains an open question. However, it is worthy to note that a reduction of fat in diet to meet a ratio of 1.63:1 fat to carbohydrate and protein ratio (Diet B) may lead to a ketosis state that is at least as efficient as the ketosis buildup at high fat diet content of 3.80:1 fat:(carbohydrates + protein)) (Diet C). This eliminate cumbersome ultra-high fat needs in ketogenic diets, which are typically associated with nausea and non-compliance [33,34]. A reduction in fat ratio also would mean more food choices to be available which may improve the diet compliance especially in epileptic children under such diets.

In addition, there are several significant observations in the kinetics of acetone buildup among individuals. As an example, Figure 3 shows the acetone buildup among the 11 subjects during starvation (phase 3: Day 7) following Diet B (1.6:1 fat:(carbohydrates + protein)) on Day 6 (phase 2). The data shows that individuals are different not only in their acetone levels but also in their acetone growth kinetics. This variability indicates the need for personal monitoring of breath acetone in order to choose the most effective diets for development of ketosis in healthy individuals, which leads to investigation of the physical and physiological factors in individuals that determine acetone buildup capability.

Figure 4 shows correlations of breath acetone levels with blood ketone, urinary ketone, and blood glucose. The very high breath acetone levels collected from all 11 subjects were confirmed with the high blood ketone and urinary ketone levels. In addition, the exponential decay relationship between breath acetone and blood glucose also indicated that blood glucose was depleted as breath acetone was produced.

\section{Ketone buildup capability}

The increase in acetone levels so-called fasting ketosis capability was correlated with different physiological and physical parameters recorded during the study. Figure 5 shows parameter relationships and correlation plots for acetone buildup for Day 7 of Diet $C$ with BMI, TEE, and body fat percentage (\%). There was an exponential decay tendency in the acetone production with

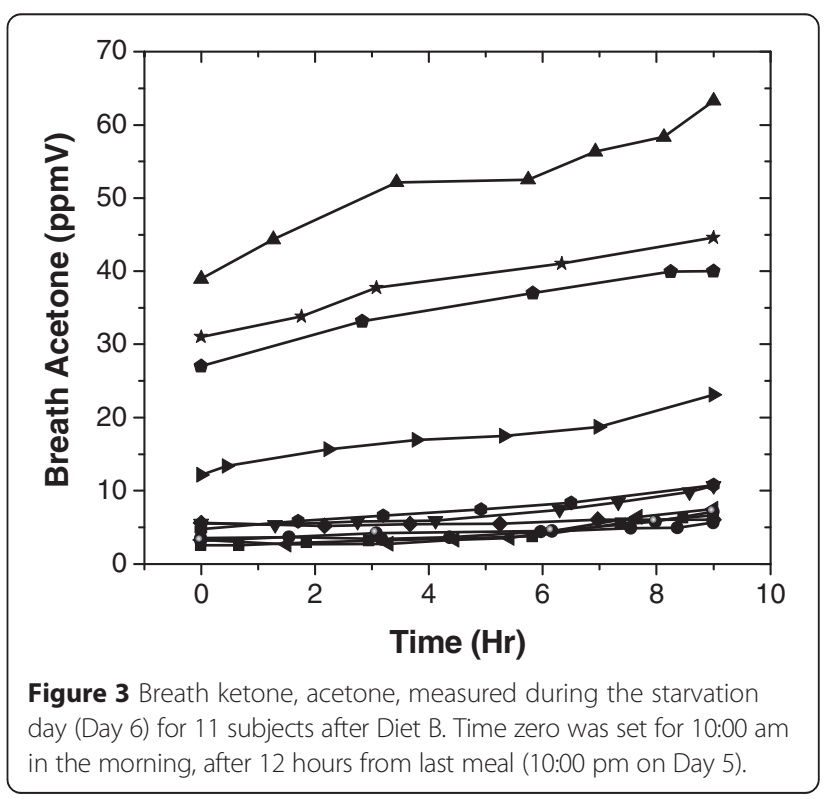



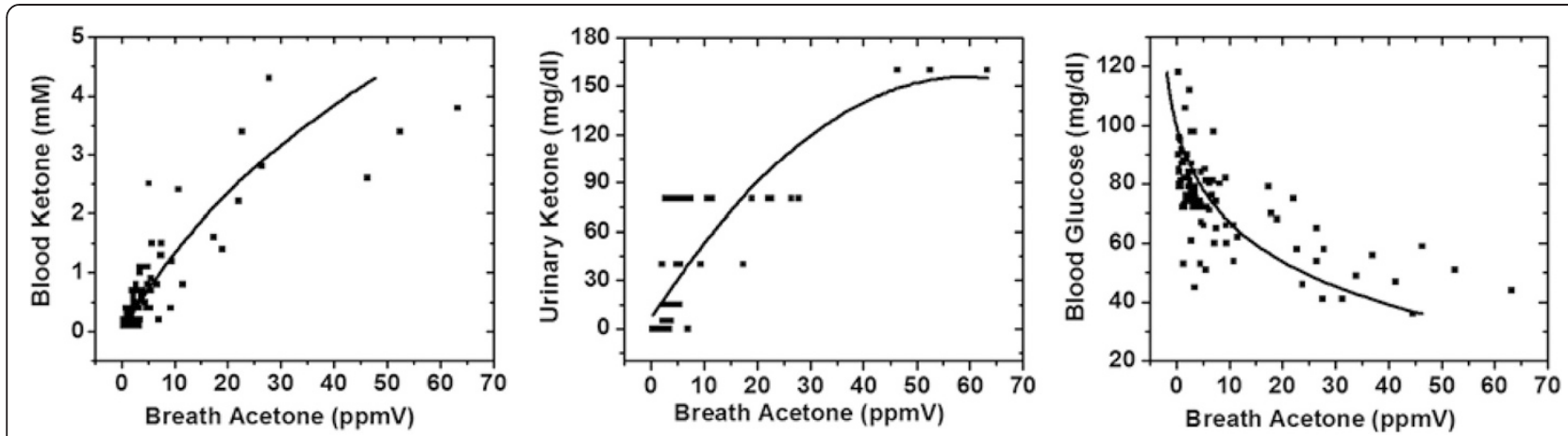

Figure 4 Correlation of breath acetone levels with blood ketone and urine ketone as well as blood glucose collected from different subjects on their fasting days.

both BMI $\left(R^{2}=0.46\right)$ and body fat $\%\left(R^{2}=0.71\right)$. Though the correlation was weaker with BMI, both correlations still presented the general tendency that subjects with lower BMI produced more acetone. This finding was in agreement with former assessments presented in literatures [35,36]. At the beginning of the day, 12 hours after the last meal, collected breath acetone in each individual showed expected levels. All subjects on Diet A of low fat/high carbohydrates, produced less than $1 \mathrm{ppmV}$ acetone; while subjects on Diet B and C, ketogenic diets, produced significantly higher acetone levels.

The increase in breath acetone levels has previously been reported by Smith, Španěl et al. [32,37]. However, the absolute values of acetone buildups from this study are higher than previously reported studies (as seen in Table 4). The reasons of the differences are rationalized as follows:

1) We have observed that during a fasting period, the time from last meal triggers an exponential growth in acetone levels. Our fasting times are considerably longer, 2.5 to 3 times longer than previously reported values from literature, which were 8 hours at the most (e.g. from 8:00 am to 4:00 pm) [32].

2) Furthermore, the fat content of the diets administered 22 hours prior to the fasting period of this study are at least 3 to 4 times higher than those used in the previously reported ketogenic diet studies [37].

As a result, this study shows higher levels compared to the previous studies due to higher fat content in the diets combined with a longer fasting period of 22 hours.

The higher levels of ketone buildup were also verified by high urine and blood ketone measurements (up to $4.4 \mathrm{mM}$ ), as shown in Figure 4. The methods used for this verification were validated in a previous study that had successfully used the methods to screen ketosis cases in a subject's population [38]. In addition, the assessed values of urine, blood, and breath ketone for this study were also found to correlate with the urine, blood, and breath acetone levels found in a high ketoacidosis group reported by Qiao, Hu, et al. [18].

Another interesting observation of this study is related to acetone buildup in correlation with BMI, body fat \%,
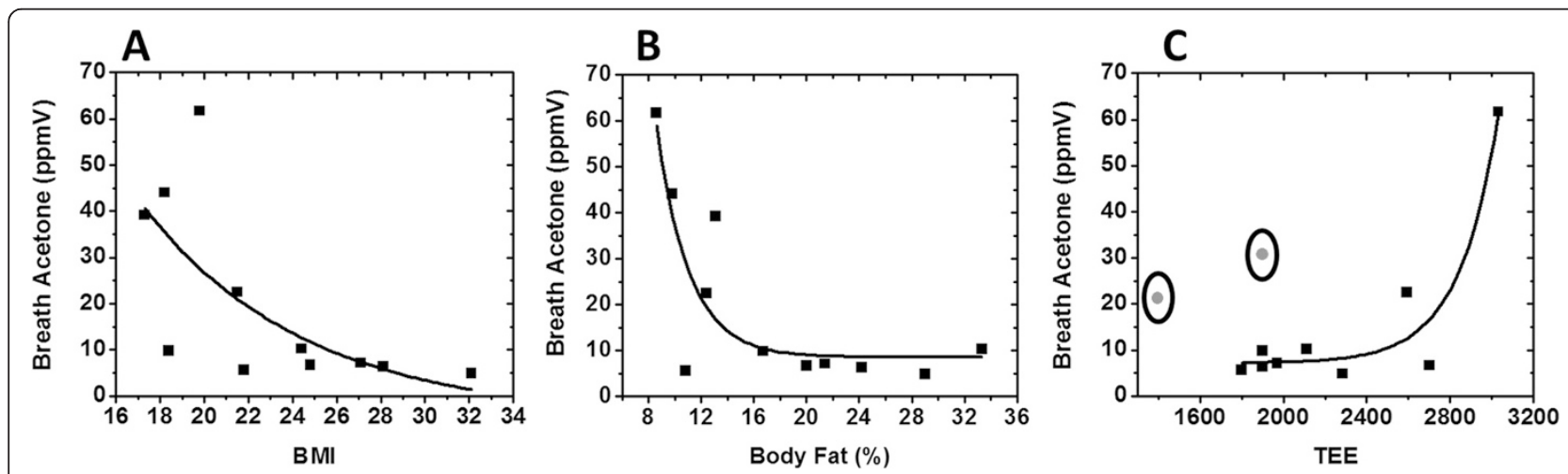

Figure 5 Correlation of acetone buildup on starvation day (Day 6) after diet C (on Day 5) with different physiological parameters. (A) Exponentially decaying correlation of acetone buildup with BMI $\left(R^{2}=0.46\right)$, (B) Exponentially decaying correlation of acetone buildup with Body Fat $\%\left(R^{2}=0.71\right)$, and (C) Exponentially increasing correlation of acetone buildup with TEE (TEE $=$ PAL $\times R E E$, for more details see experimental section) $\left(R^{2}=0.92\right.$ for $\left.n=9\right)$. Two subjects with lowest BMI (marked in circles) did not follow the trend likely due to non-compliance of energy balanced diet on Day 5 of the diet. 
Table 4 Comparative table of acetone buildup conditions for this study and other studies

\begin{tabular}{|c|c|c|c|c|c|c|}
\hline Reference & Conditio & ning Diet & Diet prior tc & acetone testing & Condition during testi & \\
\hline & Period & Composition & Period & Composition & Condition & Period \\
\hline This work & Day 1-5 & $\begin{array}{l}\text { fat:(carbohydrate + protein) } \\
\text { by mass of } 0.18 \text { or the } \\
\text { equivalence of } 29 \% \text { energy } \\
\text { from fat }\end{array}$ & Day 6 & $\begin{array}{l}\text { Diet } B^{*} \text { : fat:(carbohydrate + protein) } \\
\text { by mass of } 1.63, \text { or } 78 \% \text { energy from fat }\end{array}$ & Fasting since last meal & $22 \mathrm{hrs}$ \\
\hline Ref. 37 & & & Single meal & $\begin{array}{l}\text { liquid protein-energy meal**: } \\
\text { Fat:carbohydrate + protein) by mass: } \\
12 \mathrm{~g} / 49 \mathrm{~g} ; 0.24\end{array}$ & Fasting since last meal & $4-5$ hrs \\
\hline Ref. 32 & & & & & $\begin{array}{l}\text { Diet with } 20 \mathrm{~g} \\
\text { carbohydrate/day*** }\end{array}$ & $\begin{array}{l}8 \text { hrs/day } \\
\text { during } 12 \text { days }\end{array}$ \\
\hline
\end{tabular}

and REE. Subjects with lower BMI and body fat \% seemed to produce higher levels of breath acetone compared to the rest. Additionally, when combining ketogenic diets with fasting for the next 9 hours, we found exponential growth of acetone levels from all subjects. Acetone levels as high as 35-65 ppmV were observed for subjects with lower BMI and body fat \%.

Furthermore, the trend of acetone buildup with TEE was interesting because for nine of eleven subjects (see below), the data showed a strong exponentially increasing trend $\left(R^{2}=0.92\right)$. Since TEE values are a direct measure of REE values (TEE $=$ PAL * REE, with PAL corresponding to sedentary level for all subjects of the study), the trend was indicative of the direct correlation between ketosis buildup or fasting ketosis capability and metabolic rates. This is a conclusion that requires further investigation, but in principle, it should be expected that higher metabolic rates might correlate with higher fat burning capabilities, and therefore higher ketone buildup in healthy individuals under NK and FK states. It is worth noticing, the remaining 2 subjects (outliers of the general trend), had relatively low metabolism, and with the least BMI among all the 11 subjects. An interview with the subjects the next morning revealed they did not comply with the assignment of consuming completely their total supply of food on Day 6. Therefore, the higher acetone changes may have been a result of negative energy balance (calorie intake was less than their TEE), a condition that deviates from the one applied to the other 9 subjects, and increases fat oxidation rates from the body's stored fat.

The collected and analyzed results brought some important insights into the common high fat/low carbohydrate or very low carbohydrate ketogenic diets, particularly as they are applied to individuals. Higher fat content diet did not always induce the most breath acetone, which correlates to fat oxidation. However, more in-depth research needs to be performed to draw further conclusions since our study only examined ketosis buildup over one day of a ketogenic diet and one day of fasting. Additionally, one small drawback was that the highest fat diet was very difficult to consume. As a result, it was hard to recruit more subjects.

\section{Conclusions}

In conclusion, the data presented in this study show that while Nutritional Ketosis (NK) is an effective way to control ketone levels, NK has a great impact on FK in terms of ketone production, which is desirable in certain cases such as seizure control in epilepsy. Though ratio of fat:(carbohydrate + protein) by mass of 3.80 or the equivalence of $90 \%$ energy from fat, a high-fat diet that is most commonly recommended in NK for treatments, the data from this paper show that it may not be necessary for everyone. On the contrary, most subjects in this study showed similar or better ketosis buildup with a diet of lower fat content. These observations suggest the need for personalized monitoring of individuals for optimization of their diet. Variations in the subject's ability to produce acetone were found to correlate with several physiological and physical parameters. For example, the correlations indicated that subjects with lower fat percentage, BMI, as well as higher metabolic rate (REE) have higher ketone buildups, and thus metabolize fat more efficiently.

\section{Additional file}

Additional file 1: Supplementary data.

Competing interests

The authors declare that they have no competing interests.

\section{Authors' contributions}

AP and AQ conducted the research and analyzed the data. DJ and MT contributed in the understanding of ketosis and recruited subjects. HZ ensured acetone data was indicator of fat oxidation, FT provided SIFT-MS support. XX provided miscellaneous support. NT provided support and valuable discussions. EF designed the study, managed the diets, and logistics (IRB). All authors read and approved the final manuscript. The authors acknowledge Sunanda Vittal for helping with the English editing of 
the manuscript, and to Dr. David Smith, and Dr. Jonathan Little for the essential comments and suggestions that contributed to key improvements of this article.

\section{Acknowledgements}

We would like to acknowledge compliances from all 11 subjects of the diet study and financial assistance from School for Engineering of Matter, Transport, and Energy, Arizona State University.

\section{Author details}

${ }^{1}$ Current address: Center for Bioelectronics and Biosensors, the Biodesign Institute, Arizona State University, 1001 S McAllister Ave., Tempe, AZ 85287, USA. ${ }^{2}$ School for Engineering of Matter, Transport, and Energy, Arizona State University, 501 E. Tyler Mall, Tempe, AZ 85287, USA. ${ }^{3}$ School of Electrical, Computer, and Energy Engineering, Arizona State University, 650 E. Tyler Mall, Tempe, AZ 85281, USA.

\section{Received: 11 August 2014 Accepted: 10 April 2015}

\section{Published online: 22 April 2015}

\section{References}

1. Veech RL, Chance B, Kashiwaya Y, Lardy HA, Cahill GF. Ketone bodies, potential therapeutic uses. IUBMB Life. 2001;51:241-7.

2. Charles R, Bee Y, Eng P, Goh S. Point-of-care blood ketone testing: screening for diabetic ketoacidosis at the emergency department. Singapore Med J. 2007:48:986-9.

3. Frayn K. Metabolic Regulation: A Human Perspective (3rd Edition). United Kingdom: Wiley-Blackwell; 2010.

4. Brehm BJ, Seeley RJ, Daniels SR, D'Alessio DA. A randomized trial comparing a very low carbohydrate diet and a calorie-restricted low fat diet on body weight and cardiovascular risk factors in healthy women. J Clin Endocrinol Metabol. 2003:88:1617-23.

5. Bueno NB, De Melo ISV, De Oliveira SL, Da Rocha Ataide T. Very-lowcarbohydrate ketogenic diet v. low-fat diet for long-term weight loss: A meta-analysis of randomised controlled trials. Br J Nutr. 2013;110:1178-87.

6. Paoli A, Rubini A, Volek J, Grimaldi K. Beyond weight loss: a review of the therapeutic uses of very-low-carbohydrate (ketogenic) diets. Eur J Clin Nutr. 2013;67:789-96

7. Vining EP. The ketogenic diet. Adv Exp Med Biol. 2002;497:225-31.

8. Garrow JS. Energy balance and obesity in man. Amsterdam/London: North-Holland Publishing Company; 1974.

9. Keene DL. A systematic review of the use of the ketogenic diet in childhood epilepsy. Pediatr Neurol. 2006:35:1-5.

10. Mitchell G, Kassovska-Bratinova S, Boukaftane Y, Robert M, Wang S, Ashmarina L, et al. Medical aspects of ketone body metabolism. Clin Invest Med. 1995;18:193-216.

11. Mattson MP, Wan R. Beneficial effects of intermittent fasting and caloric restriction on the cardiovascular and cerebrovascular systems. J Nutr Biochem. 2005;16:129-37.

12. Johnson JB, Summer W, Cutler RG, Martin B, Hyun D-H, Dixit VD, et al. Alternate day calorie restriction improves clinical findings and reduces markers of oxidative stress and inflammation in overweight adults with moderate asthma. Free Radic Biol Med. 2007;42:665-74.

13. Yancy WS, Olsen MK, Guyton JR, Bakst RP, Westman EC. A Low-carbohydrate, ketogenic diet versus a Low-Fat diet to treat obesity and HyperlipidemiaA randomized. Controlled trial. Ann Intern Med. 2004;140:769-77.

14. Koeslag J. Post-exercise ketosis and the hormone response. Med Sci Sports Exerc. 1982;14:327-34.

15. Sasaki H, Ishikawa S, Ueda H, KIMURA Y. Response of acetone in expired Air during graded and prolonged exercise. Adv Exerc Sports Physiol. 2011;16:97-100.

16. Musa-Veloso K, Likhodii SS, Cunnane SC. Breath acetone is a reliable indicator of ketosis in adults consuming ketogenic meals. Am J Clin Nutr. 2002;76:65-70.

17. Musa-Veloso K, Likhodii SS, Rarama E, Benoit S, Liu Y-mC, Chartrand D, et al. Breath acetone predicts plasma ketone bodies in children with epilepsy on a ketogenic diet. Nutrition. 2006;22:1-8.

18. Qiao Y, Gao Z, Liu Y, Cheng Y, Yu M, Zhao L, et al. Breath ketone testing: a New biomarker for diagnosis and therapeutic monitoring of diabetic ketosis. BioMed Res Int. 2014;2014:1-5.
19. Smith D, Španěl P. Selected ion flow tube mass spectrometry, SIFT-MS; new horizons in real time air and breath analysis. Spectrosc Eur. 2010;22:21-4.

20. Španěl $P$, Smith $D$. Selected ion flow tube: a technique for quantitative trace gas analysis of air and breath. Med Biol Eng Comput. 1996;34:409-19.

21. Smith D, Španěl P. Selected ion flow tube mass spectrometry (SIFT-MS) for on-line trace gas analysis. Mass Spectrom Rev. 2005;24:661-700.

22. Smith $D$, Wang $T$, Španĕl P. Analysis of ketones by selected ion flow tube mass spectrometry. Rapid Commun Mass Spectrom. 2003;17:2655-60.

23. Wallace TM, Meston NM, Gardner SG, Matthews DR. The hospital and home use of a 30-second hand-held blood ketone meter: guidelines for clinical practice. Diabet Med. 2001;18:640-5.

24. Byrne H, Tieszen K, Hollis S, Dornan T, New J. Evaluation of an electrochemical sensor for measuring blood ketones. Diabetes Care. 2000;23:500-3.

25. American Diabetes Association. [http://www.diabetes.org/living-with-diabetes/ treatment-and-care/blood-glucose-control/checking-for-ketones.html]

26. Ainsworth BE, Haskell WL, Whitt MC, Irwin ML, Swartz AM, Strath SJ, et al. Compendium of physical activities: an update of activity codes and MET intensities. Med Sci Sports Exerc. 2000;32:S498-504

27. Hagstromer M, Oja P, Sjostrom M. The International Physical Activity Questionnaire (IPAQ): a study of concurrent and construct validity. Public Health Nutr. 2006:9:755-62.

28. Minh TDC, Blake DR, Galassetti PR. The clinical potential of exhaled breath analysis for diabetes mellitus. Diabetes Res Clin Pract. 2012;97:195-205.

29. McArdle WD, Katch Fl, Katch VL. Exercise physiology: nutrition, energy, and human performance, Chapter 9: Human Energy Expenditure during Resting and Physical Activity. Philadelphia, PA: Lippincott Williams \& Wilkins; 2010.

30. Xian X, Quach A, Bridgeman D, Tsow F, Forzani E, Tao N. Personalized metabolic analyzer for Energy Expenditure (EE) measurment. Global J Obes Diabetes Metabol Syndrome. 2015;2:5.

31. Zhao D, Xian X, Terrera M, Krishnan R, Miller D, Bridgeman D, et al. A pocket-sized metabolic analyzer for assessment of resting energy expenditure. Clin Nutr. 2014;33:341-7.

32. Španěl P, Dryahina K, Rejšková A, Chippendale TW, Smith D. Breath acetone concentration; biological variability and the influence of diet. Physiol Meas. 2011;32:N23

33. Lightstone L, Shinnar S, Callahan CM, O'Dell C, Moshe SL, Ballaban-Gil KR. Reasons for failure of the ketogenic diet. J Neurosci Nurs. 2001;33:292-5.

34. Mak S, Chi C, Wan C. Clinical experience of ketogenic diet on children with refractory epilepsy. Acta Paediatr Taiwan. 1999;40:97.

35. Thomas CD, Peters JC, Reed GW, Abumrad NN, Sun M, Hill J. Nutrient balance and energy expenditure during ad libitum feeding of high-fat and high-carbohydrate diets in humans. Am J Clin Nutr. 1992;55:934-42.

36. Blaak EE, Hul G, Verdich C, Stich V, Martinez A, Petersen M, et al. Fat oxidation before and after a high fat load in the obese insulin-resistant state. J Clin Endocrinol Metabol. 2006:91:1462-9.

37. Ajibola OA, Smith $D$, Španěl $P$, Ferns GA. Effects of dietary nutrients on volatile breath metabolites. J Nutr Sci. 2013;2:e34.

38. Prabhakar A, Quach A, Wang D, Zhang H, Terrera M, Jackemeyer D, et al. Breath Acetone as Biomarker for Lipid Oxidation and Early Ketone Detection. Global J Obesity Diabetes Metab Syndrome .2014:1-8.

\section{Submit your next manuscript to BioMed Central and take full advantage of:}

- Convenient online submission

- Thorough peer review

- No space constraints or color figure charges

- Immediate publication on acceptance

- Inclusion in PubMed, CAS, Scopus and Google Scholar

- Research which is freely available for redistribution 